American Journal of Applied Sciences 3 (7): 1905-1909, 2006

ISSN 1546-9239

(c) 2006 Science Publications

\title{
A Competence-based View to Conflict Management
}

\author{
Waitchalla R.R.V. Suppiah and Raduan Che Rose \\ Graduate School of Management, University Putra Malaysia, 43400 UPM \\ Serdang, Selangor Darulehsan, Malaysia
}

\begin{abstract}
This study presents a review of conflict management from the competence-based perspective. It highlights the conflict management typologies as well as previous studies conducted using the competence model of conflict. There are scant studies using the competence model to conflict management. Previous studies using this model have used students as their respondents and have a Western biasness.
\end{abstract}

Key words: Conflict, conflict management styles, competence, effectiveness, appropriateness

\section{INTRODUCTION}

Conflict is a pervasive aspect in both professional and social interactions. It occurs among family members, friends, colleagues and even between superiors and subordinates. As long as there is a human element present, conflict is certain.

No doubt when mentioning the word conflict, the first thing that comes to mind is that it is a negative and a destructive element to be avoided at all costs. In addition, other issues associated with conflicts are wasted time on conflicts ${ }^{[1-4]}$, low employees motivation $^{[2,3,5,6]}$, lower productivity ${ }^{[1,3,5]}$, equipment being stolen or vandalized ${ }^{[1,2]}$, increased legal costs ${ }^{[1,5]}$, relational strain in the workplace ${ }^{[7]}$, negative consequences for health ${ }^{[8]}$ and stressed-related medical claims $^{[5]}$. Furthermore, decisions made by people in conflict will not be the best as angry colleagues might withhold or manipulate information required by decision makers and decision makers' judgments are marred when they feel threatened by the other's intentions.

Conflicts in the workplace are not something to be ignored. Unaddressed conflicts will fester and get worse if it is neglected. Individuals need to have the skills and knowledge on how to manage the conflict as competently as possible when the inevitable conflict surfaces. More so, since management of conflict is one of the important roles played by managers in organizations ${ }^{[9]}$ as managing workplace conflict is one of the crucial investment for long term viability and success for a business ${ }^{[10]}$. In addition, it was found that managers spent in excess of $20 \%$ of their time dealing with conflict ${ }^{[11]}$.

Cetin and Hacifazlioglu ${ }^{[12]}$ argued that the way a conflict is handled would affect the nature of the conflict, that is, whether it becomes beneficial or destructive. The benefits of conflict should not be underestimated. Conflict which is managed effectively and appropriately would add substantial value to an organization, as it is considered as a healthy ingredient in business life ${ }^{[13]}$ in addition to acting as a catalyst for change agent ${ }^{[14-16]}$. Conflicts which are managed well will create a conducive workplace for its workers where relationships, trust and respect will prevail among its employees $^{[17]}$. Having such working environments will result in stimulated team spirit and increased productivity. Furthermore, with strengthened working relationships, the "us" versus "them" polarization can be eliminated ${ }^{[18]}$. This is crucial as good working relationships are important to achieve organizational goals. Damaged relationships would hinder future work together initiatives.

Conflict: There is no one comprehensive definition of conflict as it depends on which perspective one is looking from. Definitions have been given from various disciplines such as psychology, behavioral sciences, sociology, communication and anthropology. However, the common dominant theme in these definitions are the aspects of differing needs, goals, or interests and the perceived or real interference from one party unto the other party to achieve these needs, goals or interests. Perception plays an important role in conflict. If the conflict is not perceived by either party, then it does not exist. However, when the conflict is perceived, it occurs whether or not the perception is real.

Conflict management typologies: There are various styles that can be used to handle conflicts. Follett ${ }^{[19]}$ discovered three main ways to handle conflict: domination, compromise and integration. She also found others such as avoidance and suppression. Blake and Mouton ${ }^{[20]}$ were the first to present the conceptualization of the five conflict styles for managing interpersonal conflict. They classified the five conflict management styles as problem-solving, smoothing, forcing, withdrawal and sharing. These

Corresponding Author: $\quad$ Waitchalla R.R.V. Suppiah, Graduate School of Management, University Putra Malaysia, 43400 UPM, Serdang, Selangor Darulehsan, Malaysia, Tel: 6012-3039624 
styles were based on two dimensions in relation to the attitudes of the manager; concern for production and concern for people. They drew up these dimensions on nine-point scales to form the grid. The horizontal axis represents concern for production while the vertical axis represents concern for people. The 1 end represents low concern while the 9 depicts the highest concern. Blake and Mouton ${ }^{[21]}$ also noted that though one of these styles may be dominant in an individual's actions, however, it might be changed to another, if the first is not effective. These styles were later relabeled by Thomas $^{[22]}$ as avoiding, accommodating, competing, compromising and collaborating based on two intentions of an individual; cooperativeness and assertiveness. In cooperativeness, one party attempts to satisfy the other party's concerns, while in assertiveness the party attempts to satisfy its own concern. Using the conceptualization by Blake and Mouton ${ }^{[20]}$ as well as Thomas [ ${ }^{22]}$, Rahim and Bonoma ${ }^{[23]}$ categorized conflict management styles into avoiding, obliging, dominating, compromising and integrating. Their model was based on two orthogonal dimensions; concern for self and concern for others. Other researchers have also focused on the dual concern model by using different terminologies. Among them, Conerly and Tripati ${ }^{[24]}$ provided a dual concern model with the dimensions centered on how much one cared about achieving one's goals - how assertive one was and the second dimension on how much one cared about the relationships - how cooperative one was. Their five conflict management styles based on these two dimensions were withdrawing, forcing, smoothing, confronting and compromising. Masters and Albright ${ }^{[25]}$ presented a dual concern model which focused on what was valued: the relationship or the outcome. With this, they also proposed five conflict management styles; avoidance, competition, accommodation, collaboration and compromise. Besides these five conflict management styles based on the dual concern models, there have been others who have suggested two ${ }^{[26,27]}$, three $^{[28,29]}$, four ${ }^{[30,31]}$, seven ${ }^{[32,33]}$, eight ${ }^{[34]}$ and nine ${ }^{[35]}$ styles to handle conflict.

Competence-based view to conflict: Spitzberg and Canary $^{[36]}$ and Canary and Spitzberg ${ }^{[37,38]}$ used the competence-based view to conflict to describe how people managed their disputes. Though this model was initially used in association to personal relationships, recent studies have used it in organizational settings as well ${ }^{[39]}$. Papa and Canary ${ }^{[40]}$ have outlined three features to the competence-based view to conflict.

The first feature centers on the impressions of an individual's communicative behavior, not just the behavior itself. In a conflict, it is important to know how an individual's behavior is perceived as it can be interpreted in different ways. For example, a supervisor might threaten his subordinate with a bad performance report if the subordinate fails to complete the project by a certain dateline. As such, though such a threat is perceived as inappropriate, in this instance it is an appropriate approach.

The second feature to the competence-based approach to conflict focuses on two behavioral criteria that are linked to communication quality namely; appropriateness and effectiveness. Appropriateness refers to "communication that avoids violation of relationally or situationally sanctioned rules, whereas effectiveness refers to communication that achieves the valued objectives of the interactant" (p.154) ${ }^{[40]}$. Canary and Spitzberg ${ }^{[37]}$ discovered two appropriateness factors; general appropriateness and specific appropriateness. General appropriateness (also known as situational appropriateness) relates to the evaluation of the individual's behavior over the whole conflict episode. It focuses on the ability of the individual to conduct a polite conversation and adapt to the situation. Specific appropriateness (also known as relational appropriateness) concerns particular behaviors acted by the individual during the conflict episode. It focuses on to behavior that is generally prosocial and constructive in nature.

A partner's competence is influenced more by appropriateness than effectiveness while assessments of one's own competence are determined more by effectiveness than appropriateness ${ }^{[36,38]}$.

Spitzberg, Canary and Cupach ${ }^{[41]}$ crossed appropriateness and effectiveness as dimensions which resulted in a grid with four cells. This grid depicts the various combinations of appropriateness and effectiveness. An individual who is inappropriate and ineffective does not follow rules and does not attain desired goals. This individual's interaction is minimizing in orientation. An individual is seen as sufficing when he is appropriate but not effective. This individual is neither doing anything wrong nor does he obtain valued objectives through interaction. An individual who maximizes is effective but inappropriate as he is able to attain valued objectives but he violates standards of relational preference. The individual who is both appropriate and effective is one who obtains valued objectives while maintaining the integrity of the interaction. This grid is similar to the conflict styles grid and management styles as postulated by Blake and Mouton $^{[20,21]}$. If the conflict management styles are overlaid with the appropriateness and effectiveness, it will look like Fig. 1.

Competing behavior is similar to a maximizing orientation where the individual has no care for the consequences to the other person. Avoiding relates to a minimizing orientation where the individual is unable to fulfill his own as well as the other person's expectations. An accommodating conflict management style is when the individual is very concerned about appropriateness as compared to fulfilling his interests 


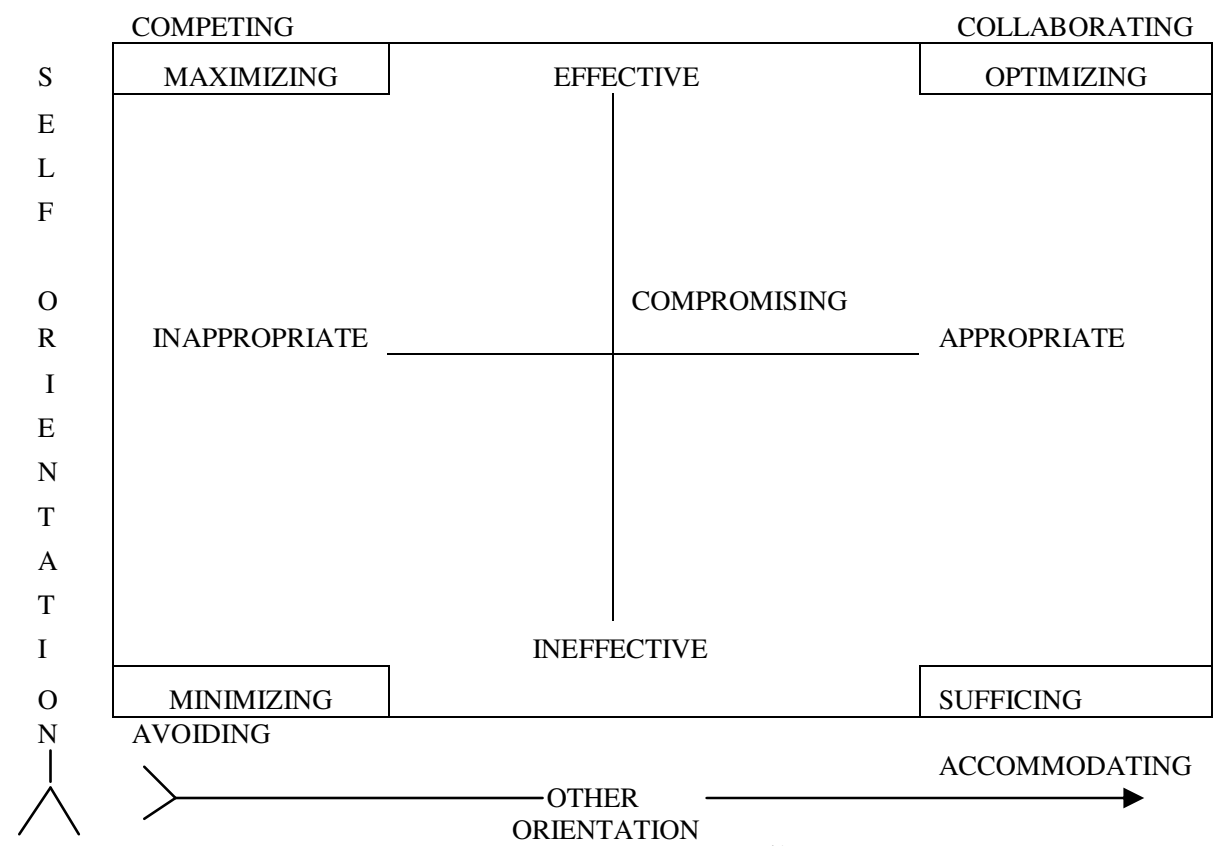

Fig. 1: Source: Adapted from Spitzberg, Canary and Cupach ${ }^{[41]}$. In Conflict in Personal Relationships. p. 186

which is similar to the sufficing response. A compromise is achieved when the individual seeks a middle path to self and other's interest. In the collaborating style, a win-win formula is practiced in producing an optimal response. Here "appropriateness ensures that care is shown to the other parties' interests and expectations, while effectiveness represents a pursuit of self's interests" ${ }^{\text {"[41] }}$.

The final feature of the competence-based approach looks at how the conflict behaviors are evaluated on competence which is linked to relational outcomes $^{[38,42]}$. Research has shown that perceptions of competence mediate the relationship between conflict behaviors and relational features ${ }^{[40]}$. This means that when two conflicting parties manage a conflict successfully in terms of appropriateness and effectiveness, the relationship between them is preserved in addition to having the conflict resolved.

Previous Studies on Competence (Effectiveness and Appropriateness) and Conflict: There is scant research in conflict studies using the competence approach. Previous studies using the competence approach to conflict by Canary and Spitzberg ${ }^{[37,38,43]}$, Canary and Cupach $^{[42]}$ and Canary, Cupach and Serpe ${ }^{[44]}$ have focused on personal relations with students as their respondents. Gross and Guerrero ${ }^{[45]}$ and Gross, Guerrero and Alberts ${ }^{[46]}$ used a simulated organizational decision-making task but their respondents were still students. The exception was a study by Boonsathorn ${ }^{[39]}$ who used managers (dyads of peers) in MNC's in Thailand as her respondents.

The studies by Canary and Spitzberg ${ }^{[37,38,43]}$, Canary and Cupach ${ }^{[42]}$ as well as Canary et al. ${ }^{[44]}$ found that integrative tactics have been consistently related to competence while distributive tactics have been negatively associated to competence. Avoidance was negatively linked with competence. Integrative tactics are conflict strategies which are cooperative, distributive tactics are competitive and antagonistic while avoidant tactics are attempts to diffuse discussion of conflict. Gross and Guerrero ${ }^{[45]}$ reported that integrative style was generally perceived as the most appropriate and effective. Dominating style tended to be perceived as inappropriate when used by others but some judged themselves as more effective when using dominating tactics along with integrating tactics. Obliging style was generally perceived as neutral. However, some perceived themselves to be less effective and relationally appropriate when they used obliging styles. Avoiding style as generally perceived as relatively ineffective and inappropriate while some judged their partners to be more effective and relationally appropriate if they compromised. Gross et $a l .{ }^{[46]}$ found that solution-oriented strategy was perceived as effective and appropriate. People rated themselves as more effective when they used controlling strategy but they perceived their partner's use of such a strategy as inappropriate.

Majority of these studies represent a Western bias with the exception of the study by Boonsathorn ${ }^{[39]}$. Though the Western studies found certain conflict styles such as obliging as ineffective and appropriate and avoiding as ineffective and inappropriate however, Ting-Toomy ${ }^{[47]}$ asserted that avoiding and obliging conflict management styles are seen by many Asian cultures as effective and appropriate. This is because these styles are utilized to maintain relational harmony. It should be noted however, that this opinion contradicts the findings by Boonsathorn ${ }^{[39]}$ where Thai respondents did not rate avoiding and obliging highly. 
As such, more studies using the competence model should be encouraged in conflict management.

\section{CONCLUSION}

The competence model has been underutilized in previous conflict studies since most of the past studies have used students as the respondents and have a Western bias. The model has been focused on social settings. As such, there should be more studies using working subjects as respondents. The authors are currently undertaking a study to further this model in an Eastern setting using superior-subordinate dyads. It is hoped that the findings will further enhance the competence model. Such findings with an Eastern view would be beneficial to many be it academicians, researchers or even businessmen who would need to understand how the people on the "other side" view conflict and how best to manage conflict to bring forth an amicable and optimum solution.

\section{REFERENCES}

1. Kaye, K., 1994. Workplace wars and how to end them: Turning personal conflicts into productive teamwork. New York: AMACOM.

2. Dana, D., 2001. Conflict Resolution. Mediation Tools for Everyday Worklife. New York: McGraw Hill.

3. Adkins, B., 2003. There is a cost to the conflict within an organization. Fort Worth Business Press, 16: 9 .

4. Bacal, R., 2004. Organizational conflict: The good, the bad and the ugly. The J. Quality and Participation, 27: 2.

5. Smith, S., 2002. Managing workplace conflict. Westchester Country Business J., 42: 4.

6. Hessel, G., 2003. The cost and management of organizational conflict. New Hampshire Business Review, 25: 5.

7. Tamam, E., M.S. Hassan and Md.Y. Yaid, 1997. Intracultural interpersonal conflict-handling styles among malay middle-level executives. Malaysian Management Review, 32: 55-61.

8. De Dreu, C.K.W., D.V. Dierendonck and M.T.M. Dijstra, 2004. Conflict at work and individual wellbeing. Intl. J. Conflict Management, 15: 1.

9. Roper, G., 2005. Managing employee relations:develop interpersonal communications and conflict-management skills to better manage employee relations. HR Magazine. www.findarticles.com/p/articles/mi m3495/is 5 50/ai n13721394.

10. Oudeh, N., 1999. Solving conflicts at work. Manitoba Business, 21: 5.

11. Thomas, K.W. and W.H. Schmidt, 1976. A survey of managerial interests with respect to conflict [Electronic version]. Acad. Management J., 19: 315-318.
12. Cetin, M.O. and O. Hacifazlioglu, 2004. Conflict management styles: A comparative study of university academics and high school teachers. J. Am. Acad. Business, 5: 1/2.

13. Robbins, S.P., 1973. Conflict can be stimulating [Electronic version]. Management Review, 62: 3032.

14. Litterer, J.A., 1966. Conflict in organization: A reexamination [Electronic version]. Acad. Management J., 9: 178-186.

15. Robbins, S.P., 1978. Conflict management and Conflict resolution are not synonymous terms [Electronic version]. California Management Review, 21: 67-75.

16. Lacey, H., 2000. How to resolve conflict in the workplace. England: Gower Publishing Limited.

17. Gill, S.K., 1992. Handling conflicts. In A. Abdullah, (Ed.), Understanding the Malaysian workforce - Guidelines for managers, pp:107-115. Kuala Lumpur: Malaysian Institute of Management.

18. Pedersen, P.B. and F.E. Jandt, 1996. Culturally Contextual Models for Creative Conflict Management. In F.E. Jandt and P.B. Pedersen (Eds.) Constructive conflict management. AsiaPacific cases, pp: 3-26. Thousand Oaks: Sage Publications.

19. Follett, M.P., 1940. Constructive Conflict. In H.C. Metcalf and L Urwick (Eds.), Dynamic administration: The collected papers of Mary Parker Follett, pp: 30-49. New York: Harper and Brothers Publishers.

20. Blake, R.R. and J.S. Mouton, 1964. The managerial grid. Key orientations for achieving production through people. Houston, Texas: Gulf Publishing Company.

21. Blake, R.R. and J.S. Mouton, 1973. The fifth achievement. In F.E. Jandt, Conflict resolution through communication. New York: Harper \& Row.

22. Thomas, K.W., 1976. Conflict and Conflict Management. In M.D. Dunnette (Ed.), Handbook of Industrial and Organizational Psychology, pp: 889-935. Chicago: Rand McNally.

23. Rahim, M.A. and T.V. Bonoma, 1979. Managing organizational conflict: A model for diagnosis and intervention. Psychological Reports, 44: 323-1344.

24. Conerly, K. and A. Tripati, 2004. What is your conflict style? Understanding and dealing with your conflict style. [Electronic version] The J. Quality and Participation, 27: 16-20.

25. Masters, M.F. and R.R. Albright, 2005. Dealing with Conflict. In Management Skills: A Jossey Bass Reader, pp: 579-605. San Francisco, CA. John Wiley \& Sons.

26. Knudson, R.M., A.A. Sommers and S.L. Golding, 1980. Interpersonal perception and mode of resolution in marital conflict. J. Person. Soc. Psychol., 38: 751-763. 
27. Billingham, R.E. and A.R. Sack, 1987. Conflict tactics and the level of emotional commitment among unmarrieds. Human Relations, 40: 59-74.

28. Sillars, A.L., 1980. Attributions and communication in roommate conflicts. Communication Monographs, 47: 3.

29. Putnam, L.L. and C. Wilson, 1982. Communicative Strategies in Organizational Conflict: Reliability and Validity of a Measurement Scale. In M. Burgoon (Ed.), Communication yearbook, 6: 629652. Newbury Park, CA: Sage.

30. Smyth, R., 1977. The sources and resolution of conflict in management. Personnel J., 56: 225-226, 253.

31. Phillips, E. and R. Cheston, 1979. Conflict resolution: What works? [Electronic version]. California Management Review, 21: 76-83.

32. Sternberg, R.J. and L.J. Soriano, 1984. Styles of conflict resolution. J. Person. Soc. Psychol., 47: 115-126.

33. Morrill, C. and C.K. Thomas, 1992. Organizational conflict management as disputing process. The problem of social escalation. Human Communication Res., 18: 400-428.

34. Nicotera, A.M., 1993. Beyond two dimensions. A grounded theory model of conflict-handling behavior. Management Communication Quarterly, 6: 282-306.

35. Kindler, H.S., 1996. Managing disagreement constructively: Conflict management in organizations. Menlo Park, California: Crisp Publications, Inc.

36. Spitzberg, B.H. and D.J. Canary, 1985. Loneliness and relationally competent communication. J. Soc. Personal Relationships, 2: 387-402.

37. Canary, D.J. and B.H. Spitzberg, 1987. Appropriateness and effectiveness perceptions of conflict strategies. Human Communication Res., 14: 93-118.

38. Canary, D.J. and B.H. Spitzberg, 1989. A model of the perceived competence of conflict strategies. Human Communication Res., 15: 630-649.
39. Boonsathorn, W., 2003. Competence is in the eye of the beholder: Conflict management styles and perceived competence of conflict management styles by Thais and Americans in multinational corporations in Thailand. Unpublished doctoral dissertation, The Pennsylvania State University, United States of America.

40. Papa, M.J. and D.J. Canary, 1995. Conflict in organizations: A competence-based approach. In A.M. Nicotera (Ed) Conflict and organizations. Communicative Processes, pp: 153-179. New York: State University of New York Press.

41. Spitzberg, B.H., D.J. Canary and W.R. Cupach, 1994. A Competence-based Approach to the Study of Interpersonal Conflict. In D.D.Cahn. (Ed.), Conflict in Personal Relationships, pp: 183-202. New Jersey: Lawrence Erlbaum Associates.

42. Canary, D.J. and W.R. Cupach, 1988. Relational and episodic characteristics associated with conflict tactics. J. Soc. Personal Relationships, 5: 305-325.

43. Canary, D.J. and B.H. Spitzberg, 1990. Attribution biases and associations between conflict strategies and competence outcomes. Communication Monographs, 57: 139-151.

44. Canary, D.J., W.R. Cupach and R.T. Serpe, 2001. A competence-based approach to examining interpersonal conflict. Test of a longitudinal model. Communication Res., 28: 79-104.

45. Gross, M.A. and L.K. Guerrero, 2000. Managing conflict appropriately and effectively: An application of the competence model to Rahim's organizational conflict styles. Intl. J. Conflict Management, 11: 3 .

46. Gross, M.A., L.K. Guerrero and J.K. Alberts, 2004. Perceptions of conflict strategies and communication competence in task-oriented dyads. J. Appl. Commun. Res., 32: 3.

47. Ting-Toomy, S., 1988. Intercultural Conflict Styles. A Face-Negotiation Theory. In Y.Y. Kim and W.B. Gudykunst (Eds.) Theories in Intercultural Communication, pp. 213-235. Newbury Park: Sage Publications. 